\title{
The Emergence and Establishment of Trademark Design in Korea: from 1897 to late 1910 s
}

This paper attempts to illustrate how trademark design, as an early form of visual identity design, emerged and was established within the Korean visual culture from 1897 to the late 1910s. Since Korea (or Joseon Dynasty) remained as a closed country, trademarks were first introduced after the opening of its ports to foreign trade in 1876. The first chapter explains the import of the idea of modern capitalist trademark from the West through the Japanese colonialists. Although a trademark law was not legislated in Korea until 1908, the first appearance of a trademark as a visual symbol is found in the media from 1897. The second chapter characterizes this period between 1897 and 1908 as the 'emergence' of trademark design. During this era the inflow of foreign goods and the increase of image media such as newspapers affected trademark design. The enforcement of the trademark law in 1908, along with Japan's colonial occupation caused a turning point in Korean trademark. The number of trademarks increased rapidly, and companies started to advertise actively. The third chapter of this paper describes the period after the legislation of a trademark law until late 1910 as the 'establishment' of trademark design in Korea. Trademark designs of this era became more elaborate compared to the previous, influenced by the formation of colonial-capitalist market and the institutional protection of trademarks.

keywords trademark, identity design, Korea, East Asia

\section{Introduction}

The study on Korean trademark/visual identity design has mostly been focused on specific designs of certain industries or individual corporations. The time period these researches have dealt with has been limited to after the 1970s. This is because around this point the nation was rapidly industrialized, and large-scale identity design projects took place as corporations became aware of the importance of visually communicating their identity. The idea of CIP (or corporate identity program, a term broadly used in the field of design during this time in Korea) was introduced and became widespread among companies. From this fact, there has been a tendency in design research to define the 1970 as the starting point of visual identity design in Korea.

However, this point of view neglects numerous examples of designs before the rapid industrialization, resulting in a limited understanding of identity design in Korea. It is true that the term 'identity design' or even 'design' itself are relatively new, coming into Korea as foreign expressions. Nevertheless, although the terminology and specific visualizing techniques have changed, the basic concept of identity design and its examples are found as early as in the late nineteenth century. In order to include these abundant contexts into 
the description of the Korean design history, visual identity design should be defined more broadly as 'symbolizing products, brands or corporations through visual form', which is a part of the argument of this paper.

Under this definition, thorough research explaining how and when the symbolization of goods and organizations started, and how it is continued to the current visual culture should lead us to understand the history of visual identity design in Korea as a whole.

As part of such effort, this paper attempts to illustrate how trademark design, as an early form of visual identity design, emerged and was established within the Korean visual culture from 1897 to the late 1910s. This era is important because the earliest example of a trademark is found in 1987, and by the end of the 1910s, trademarks appear as a common form of communication within the media. Trademark was not something that naturally occurred from within the Korean culture, but a foreign importation. The Japanese were the first to start trading with Korea, by coercing to open its ports in 1876, and Western countries such as the United States, Britain and Germany followed (Kim 1993, p. 199-200). As mass-produced goods imported from Japan and the West started to compete in the Korean market, the idea of modern the capitalist trademark flowed in through the Japanese colonialists.

\section{The Modern Concept of Trademark and the Import of Trademark Laws in Asia}

According to Amino (1990 p. 7), the modern concept of trademark emerged during the Industrial Revolution in Europe. He explains that mass-production of standardized products, subdivision of the distribution process, and the beginning of open competition among manufacturers and distributors were the three main reasons for this.

When identical mass-produced products were poured into the market, a medium that could indicate that these were identical products was required. On the other hand, a device that could allow consumers to distinguish the goods they want among various products was called for. Moreover, manufacturers had to present the quality and superiority of their goods in order to attract customers after distinction was secured. Therefore the modern trademark takes the role of granting charm and authority to the product through images, as a visual symbol that capitalist economic system required.

In order to support the function of these visual symbols, the first trademark law appeared in France in 1857, and spread to other European countries and the United States. In East Asia, Japan, who had active commercial relationships with the West, was the first to legislate a trademark law in 1899. However, unlike European countries where trademark laws were naturally demanded by the market, Amino (1990, p.9-11) explains that the trademark law was forced by the government of the Meiji era, which attempted to achieve national prosperity by breaking down old customs and imitating Western institutions.

\section{The Emergence of Trademark Design in Korea: 1897-1908}

\subsection{Inflow of Foreign Products and Increase of Image Media}

In Korea, although a modern trademark law exists after a Sangpyo-ryeong (trademark order) is declared in 1908, the idea and examples of trademarks are found about ten years before this. The first visual image of a trademark is found in 1897 in The Independent (the English version of Dongnip-sinmun, a Korean newspaper), in an advertisement by the German trading company Sechang-yanghaeng (Fig. 1). Most of the advertisements 
during this period were those of Japanese and European trading companies promoting their imported products. Thus it can be understood that opening of the ports to foreign trade and the inflow of foreign goods played an essential role in introducing the capitalist product symbolization strategy to Korea.

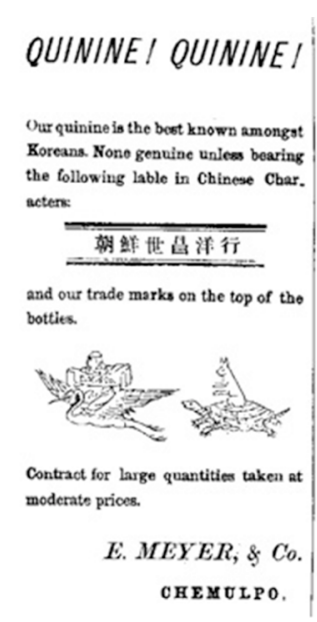

Figure 1.

Trademark shown in an advertisement of Sechang-yanghaeng (The Independent, 5 Jan, 1897)

Another important factor was the increase of image media such as newspapers. As stated above, trademarks were constantly presented through newspaper advertisements. Images were first published in Korean newspapers such as Dongnip-sinmun, Hwangseong-sinmun, Jeguk-sinmun, Daehanmaeil-sinbo. After these newspapers were first published in the late nineteenth century, communication through image became possible, and the public became familiar with product images, such as trademarks. Therefore it can be said that while the influx of foreign goods triggered the emergence of trademarks, public image media enhanced their effect by diffusing the images publicly.

\subsection{Trademark Designs as Visual attraction}

Since the appearance of Sechang-yanghaeng's trademark in 1897, a transition from text towards image in the expression of trademarks is noticeable. For example, in newspaper advertisements of Manta Drugstore from 1900 to 1903, the brand name was first presented as plain text with a same typeface as the copy, later as larger text, and then as a distinctive logotype together with a kamon (Japanese family crest) style trademark.

However, many examples show that visual consistency was lacking among trademarks in this stage. While same trademarks were presented, the individual forms varied significantly in detail (Fig. 2). For instance, BM \& Co., a British trading company selling detergents in Korea, advertised themselves with a crescent-shape trademark. Although the basic format of examples from 1899, 1901 and 1902 remains similar, difference in shape of the crescent as well as typography can be observed. The case is similar with Daikokuya, a trading company with a Japanese origin, which used the iconic figure of daikokuten (one of the Seven Gods from a Japanese myth, associated with wealth and prosperity) as a trademark. Two advertisements, of 1904 and 1905 show significant difference in detailed expression, such as the illustration of the face, overall proportion and outline. 
theme 2

memory

Figure 2. Inconsistent trademarks of BM \& Co. and Daikokuya

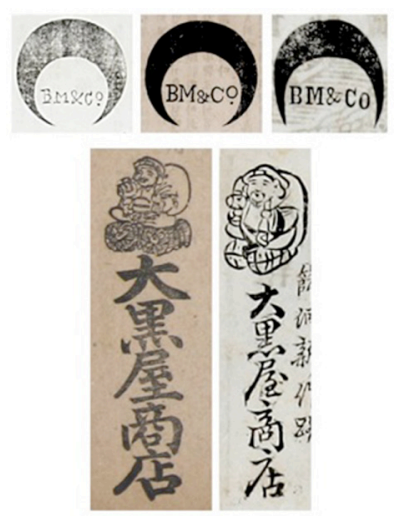

Moreover, hierarchy between corporate trademarks and product trademarks were often vague. Many examples show that multiple trademarks were presented within one advertisement, without clearly indicating what each of them represented.

The inconsistency in form reveals that 'how' to symbolize products and companies was uncertain, and the mixture of categories shows that 'what' to symbolize was unclear. Although trademarks were exhibited actively through newly introduced public media, 'what' and 'how' to represent these were obscure, which means that strong central symbols were missing.

Considering the social backgrounds of the rise of modern trademarks stated above, securing symbolic power and therefore being 'inscribed' in the minds of the public is the crucial function of trademarks. However, the effect of 'inscribing' seems to have been immature during the period of 'emergence' in trademark design.

This can be explained from the fact that the total number of public media, and the amount of products actually competing in the market was limited. Since not many companies could afford commercial advertising, only a restricted number of advertisements, or images occupied the surface of newspapers. Therefore it was important that the trademarks in advertisements were visually salient, and imprinting to the viewers a consistent symbol was relatively neglected. Thus it can be said that the primary focus of trademark designs of this period was to visually attract the eyes of the public, not as powerful symbols, but as eye-catching images.

\section{The Establishment of Trademark Design in Korea: 1908-late 1910s}

\subsection{The Formation of Colonial-Capitalist Market and the Legislation of the Korean Trademark Law}

Through the Russo-Japanese War in 1905, and the Eulsa Neukyak (Protectorate Treaty between Korea and Japan) the same year, the Japanese reinforced their control over Korea. Throughout 1905 and 1906, nationwide railroad systems were built and connected with those of Japan. According to Chung (1982, p. 120-121), this was part of the Japanese effort to enhance national competitiveness by taking advantage of Korea as a consumer market as well as a source of raw materials, as competition against the Western countries became severe. The scale of trade with Japan increased rapidly, and a large number 
Japanese merchants migrated to Korea, resulting in a formation of colonial-capitalist market, especially with Seoul as the center.

On the other hand, along with commerce being invigorated, trademark dispute became more common in Korea, therefore institutional protection of trademarks was demanded especially by Japanese companies. Eventually, the Japanese trademark law was translated intact into Korean, and the Sangpyo-ryeong was proclaimed by Emperor Sunjong in 1908 ('Trademark Notification' 1908). Moon (2002, p. 15) explains that this was forced by the Japanese colonialists in order to protect vested interests of their merchants, which consequently brought a turning point in Korean trademark design.

\subsection{Trademark Designs as 'Inscription'}

Once the Korean trademark law became effective, applications flooded in. Since legal rights were reserved for the ones registered, registered trademarks naturally became to work as an authority. Thus companies started to specify their registration by including the phrase 'registered trademark', or 'deungnok-sangpyo' explicitly in the trademark design.

The specification of registered trademarks within advertisements not only presented the authority and exclusiveness of certain trademarks, but also led companies to apply more consistent trademark designs. Unlike during the 'emergence' era, when consistency was not considered essential for visual attraction, registered trademarks had to be presented just as they were registered in the documents, in order that legal rights was approved.

Another change in trademark design during this period was that strong central symbols were designed and presented with consistency. Moreover, these symbols were shown through various expressive forms within advertisements. For example, the pharmaceutical industry was a highly competitive market, and such situation is also reflected in trademark designs of medicines of this time. Jintan, a refreshment pill from Morishita Nanyodo, was represented by an image of a man with a mustache, wearing a full-dress uniform. Hwapyeongdang, a drugstore and manufacturer of competing products of Jintan, used a plum blossom symbol as their trademark.

Both these trademarks were shown in advertisements consistently, also repeatedly within various visual contexts (Fig. 3).

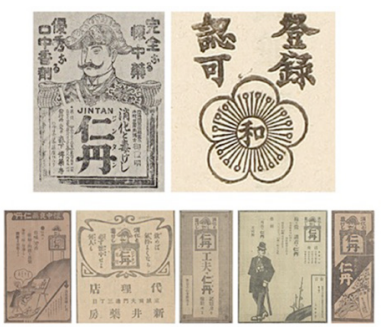

Figure 3 .

Trademarks of Jintan and Hwapyeongdang (L: Maeil-sinbo, 29 Nov, 1910, R: Maeil-sinbo, 1 Jan, 1911), and various applications of Jintan.

The explicit indication of registered trademarks and the enhancement of coherence in symbols reflect the situations of the market. As products themselves, and trademarks that represent products increased, competition became intense compared to the previous era. Therefore trademark designs that solely relied on visual attraction would have lost competitiveness. In order to overcome this, companies had to 'inscribe' their trademarks into consumers' mind, by securing consistency and repetitively exposing them to the public. If 'inscribing' can be considered as the essential quality of trademarks, it can be said 
that during this period the modern concept of trademark design was 'established' as part of the Korean visual culture.

\section{Conclusion}

The influx of foreign products after the opening of ports, and the rise of public image media became the social background of the 'emergence' of trademark design in Korea. However, because competition both in the market and in the media were not intense, the earliest trademark designs after 1897 focused mostly on visual attraction, somewhat lacking in identifying function.

In 1905 the Japanese enhanced their control over Korea, and in 1908 the Korean trademark law was legislated. The overall market/media competition became fierce, and rather naive trademark design of the previous era lost its effectiveness. Consequently, trademarks were required to take more consistent images, and to be exposed repeatedly in various contexts. Trademark design and its exposition became more elaborate, started to carry out its essential function, being inscribed to the public. Thus it can be said that trademark design was 'established' as a format of communication in Korea.

By observing the earliest examples of trademarks presented in Korean media, it was discovered that (although at first there had been some immature aspects regarding 'what' and 'how' to symbolize) by the 1910 s the conscious act of 'symbolizing products, brands or corporations through visual form' was conducted in Korea. Therefore the conventional understanding of the history of Korean visual identity design should be revised, to include various contexts which existed before the industrialization of the 1970 .

\section{References}

Amino M. (1990) Trademark (Sangpyo), Seoul: Daegwang Seorim.

Chung, J. (1982) 'On the Colonial Characters of Kyung-Bu • Kyung-Eui Railway

Transport from 1905 to 1916 in Korea (Hanmal Iljechogi Cheoldo-unsong-eui Sikminjijeok Seonggyeok)', Journal of Korean Studies (Hanguk Hakbo), vol. 3, no. 8, pp. 117-139.

Hwangseong-sinmun, $5 \mathrm{Jul}, 1904$.

Hwangseong-sinmun, 12 Jan, 1905.

Kim, H. (1993) 'A Study on Commercial Structure of the Port-opening Period and the Formation of Colonial Market System (Gaehang-gi Sang-eobgujowa Sikminji Sangeobcheje-eui Hyeongsyeong-e Gwanhan Yeongu)', Economy Research (Gyeongje Yeongu), vol. 2, no. 1, pp. 187-214.

Maeil-sinbo, 29 Nov, 1910.

Maeil-sinbo, 1 Jan, 1911.

Moon, S. (2002) Trademark Law (Sangpyobeob), Seoul: Sechang.

The Independent, 5 Jan, 1897.

'Trademark Notification' 1908, Hwangseong-sinmun, 16 Aug. 